\title{
Analysis and Design of Stadium with Truss System and Shell Roof Subjected to Wind and Seismic Loading
}

\author{
R Ashutosh V Kulkarni, Aravindkumar B Harwalkar
}

\begin{abstract}
In this paper Analysis and Design of different Structural elements of the football stadium are presented, with particular emphasis on the Combination of Steel Truss without and with Shell roof cover and its interaction with the underlying reinforced concrete structures. The Football stadium considered for the study is of rectangular plan, with $85 \mathrm{~m}$ width and $140 \mathrm{~m}$ length and height of $19.5 \mathrm{~m}$. The plan of Football Stadium is generated in AutoCAD 2016 software. The Stadium structure is composed of special moment - resisting framed. Wind velocity is taken as 39 mph and Seismic zone IV in this study. The proposed stadium is analysed using Equivàlent static and dynamic àpproach by Reșponse șpectrum ànd Time Hiṣtory ànàlysis. In anallysing the ștructure, 21 load combinations are used. The grandstand structure is made of reinforced concrete and the roof is of ștructural steel using Pipe and Tube sections. Deäd loädș, live loàds, wind änd șeismic loädingș data are considered bäsed on IS-875 (PART 1-3) 1987 and IS:1893 (Part 1):2016. IS456:2000 and SP16:1987 code is used for Design of R.C.C components such as Beäm, Column, Seating Platform, Footing and IS 800:2007 code is used for Design of End Beäring Plate connection with Truss member. Analysis of truss and other elements is carried out with software program of Staad. Pro V8i SS6 and also the designs are carried out as per provisions of relevant Indian standards. On introduction of Shell-like roof for Open Stadium which is used not only to protect the Game from Glare of Sunshine and Rain but also appears unique and attractive. From the obtained results it is observed that the displacement due to Wind action in both $X$ and $Z$ direction reduces significantly by the introduction of Shell roof. Also, due to RSA and THA there is reduction in the displacement on introduction of Shell-like roof to an Open Stadium.

Keywords: Football Stadium Roof Truss, Shell roof, Wind and Seismic analysis, Staadpro V8i SS6.
\end{abstract}

\section{INTRODUCTION}

$\mathrm{T}$

he Recent advances in science and technology, as well as increasing demands for sports and show buildings and facilities, have sparked new development across the globe. Modern stadiums are distinguished by their universality in terms of the ability to host international sporting events and

Manuscript received on August 28, 2021.

Revised Manuscript received on September 05, 2021.

Manuscript published on September 30, 2021.

*Correspondence Author

R Ashutosh V Kulkarni*, MTech Student, Department of Civil Engineering PDA College of Engineering, Kalaburgi-585102, Karnataka, India Email: revoorashu8@gmail.com

Dr Aravindkumar B Harwalkar, Associate Professor Department of Civil Engineering, PDA College of Engineering, Kalaburgi -585102, Karnataka, India. Email: harwalkar_ab@yahoo.co.in

(C) The Authors. Published by Blue Eyes Intelligence Engineering and Sciences Publication (BEIESP). This is an open access article under the CC BY-NC-ND license (http://creativecommons.org/licenses/by-nc-nd/4.0/) cultural activities. The goal of providing optimum comfort for spectators tends to be associated with fulfilling the needs of sports technology. One part of the job is to cover stands from sunshine and rain by including sheds, canopies, and roofs into the stadium's structural design. Stadiums are the grand platforms on which legends are born and fans get excitement and inspiration. Stadiums, as fascinating and significant buildings, not only enable but also enhance great shows via strong architecture and creative engineering. Structural designers have been under pressure in recent years to create the most practical, technically innovative, and architecturally renowned sports facilities. The most efficient way to track the technical development of modern stadiums throughout this time period is to look at improvements in the design of their structural roof systems.

The stadium should be modified to shield spectators from rain and blinding light in the event of a ștrong șun. Although some pretty continuous steady sunlight is typical, șhade provided by the roof should be accesssible to all open areas for at least a portion of the game, which is not always feasible. The stadium should be built such that all parameters are essentially comfortable, säfe, and șecure, and that eảch and every individual has a clear view of the court. The arrangement of seating is provided is continuous the maximum seating can be eảsily placed in stadium. In recent days, many research scholars have worked on the cover or roofed stadium. Mohini R. Gawande et al [1] carried out the study on Anàlysis and Design of Roof Tubulär Truss for Cricket Stadium and effect of wind action on the long span roof truss which should be minimized using recent technology. The Seișmic anälysis of the Cantilever truss roof of the stadium have been worked in [2] and the results showed the drift and displacements due the wind load is more when compared to earthquake load. Nonlinear Seișmic Analysis of the stadium using viscous dampers is worked out in the literature [3] and the response of the structure is obtained and they found that viscous dampers help in decreasing the displacements by $60 \%$. Dynämic monitoring of the suspenșion roof of the stadium has been worked in [4] developing a ground assessment of wind action, establish a connection with structuràl responșe, and subsequently anälysing the influence of wind and temperäture on modàl parametric variations. In literature [5] the research shows that the spatial truss structure is reasonable and able to meet the building's quality standards. Steel.

Published By:

Blue Eyes Intelligence Engineering and Sciences Publication (BEIESP) 55 (C) Copyright: All rights reserved.

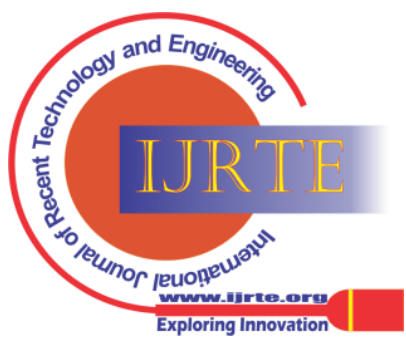


The present study is to analyse and design the stadium with steel roof truss is aimed to get a better understanding of the stadium structural analysis and design idea for steel roof truss. The Lattice truss is generally used for long span, in which the triangular and $\mathrm{N}$ - type frame arrangement taken for work. $\mathrm{N}$ and triangular frame arrangement consider the axially loaded member and N-type connection properly distributes the load acting at downward side and is distributed in node to node in whole structure. N-type truss system pattern is stronger than other arrangement for long span. They are more capable to resisting external forces or loads acting on section, to all members nearly uniformly stress. Lattice truss and $\mathrm{N}$-type trusses are proposed to be used for the present study

\section{OBJECTIVES OF THE STUDY}

1. To Develop the 3D Model of an Outdoor Stadium Structure with Truss and Shell roof Covering system.

2. To determine the behavior of the stadium structure under Static and Dynamic loading using STAAD. Pro V8i SS6 software.

3. To Design the components of the Outdoor Stadium Structure.

\section{METHODOLOGY OF THE STUDY}

This particular study includes the 3D model of Outdoor Stadium structure. The Analysis and Design of Stadiums with Truss system and Shell roof is carried out by considering deàd loảds, live loảds, wind loảds and seismic loảds for the proposed structure. And all the loảds will be designed by Indian standard codes with aid of design software STAAD. Pro V8i SS6. In this study

This project mainly emphasizes on wind and seismic analysis of the Stadium structure. The modelling of Stadium has been done on the STAAD. Pro V8i SS6 software for analysis. The parameters after the analysis of the structure such as displäcement, bảse sheảr and fundamental time period is computed. Here in this thesis, the analysis of structure evaluated in order to find the behavior with Truss system and Shell roof patterns. The șeismic zone considered is zone IV and with soil type medium. The modelling of structure is done for Indian Seișmic Zone IV, earthquake loading and wind loading are considered in the analysis. For given structure, loảding with ápplied loads includes live load, eảrthquake loảd and deảd loads are according to Indian Standards. The anälysis is taken out by Equivälent Stätic, Responșe șpectrum and Time Hiṣtory methods uṣing STAAD. Pro V8i SS6 șoftware.

\section{A. Flowchart of the Methodology:}

The methodology of the Proposed Stadium structure for the analysis and design using Staadpro V8i SS6 software is as follows

Inputs: Model creation

(Nodes, Beams, Secondary Beams and Columns)

$$
\sqrt{\Omega}
$$

Defining the material properties of the structure

$$
\text { तु }
$$

Defining Supports

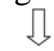

Defining loads, Assigning the loads and its combinations on the structure<smiles>[As]=[W]</smiles>

Analysis and print<smiles>[CH]=[CH]</smiles>

Run analysis<smiles>C1=CC=C1</smiles>

Outputs:

Axial force (Truss member)<smiles>[CH]=C</smiles>

Shear force diagram<smiles>[CH]1C=C1</smiles>

Bending moment diagram

凡

Deflections

,

Design: $\quad$ Reinforced concrete structures

(Beams, Columns, Platform Slabs, Footing)

If

Roof truss patter

n

Shell roof structure<smiles>[CH]1C=C1</smiles>

Conclusion

\section{B. Modeling \& problem formulation}

To model a Stadium Structure in STAAD. Pro V8i SS6, we require some preliminary data to input such as codes for design, material specifications, building specification with the dimensions of each structural component, load case, load patterns \& load combination. However, the modelling may differ from case to case. Later a brief procedure of modelling, analysis \& design of the building in STAAD. Pro V8i SS6 will be discussed as per the methodology in accordance with problem formulation.

\section{Description of the Models:}

Model-I: Outdoor Football Stadium without Shell roof cover

Model-II: Outdoor Football Stadium with Shell roof cover

Before Modelling in the Staad Software the plan of the Football stadium is created in the Auto Cad 2016 software by following the standard dimensions of the football stadium is shown in Fig 1. According to the stipulations from FIFA the standard Dimension of the football stadium is $45 \mathrm{~m}-90 \mathrm{~m}$ width and $90 \mathrm{~m}-120 \mathrm{~m}$ length. For the study $45 \mathrm{~m}$ width and $100 \mathrm{~m}$ length Play court is considered. The $3 \mathrm{D}$ Staad model of roof truss stadium without and with Shell roofing is shown below.

\section{Dimensions of the stadium}

- Overall length of the structure $=140 \mathrm{~m}$

- Overall Width of the structure $=85 \mathrm{~m}$

- Overall height of the structure $=19.5 \mathrm{~m}$

- Length of the Play court $=100 \mathrm{~m}$

- Width of the Play court $=45 \mathrm{~m}$

- Spectator Gallery $=20 \mathrm{~m}$

Published By:

Blue Eyes Intelligence Engineering and Sciences Publication (BEIESP)

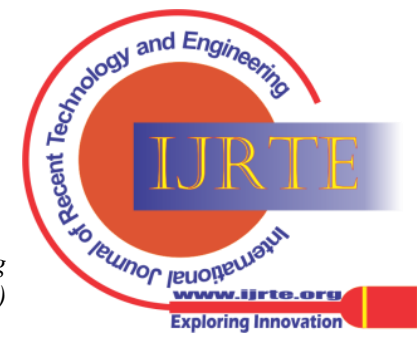




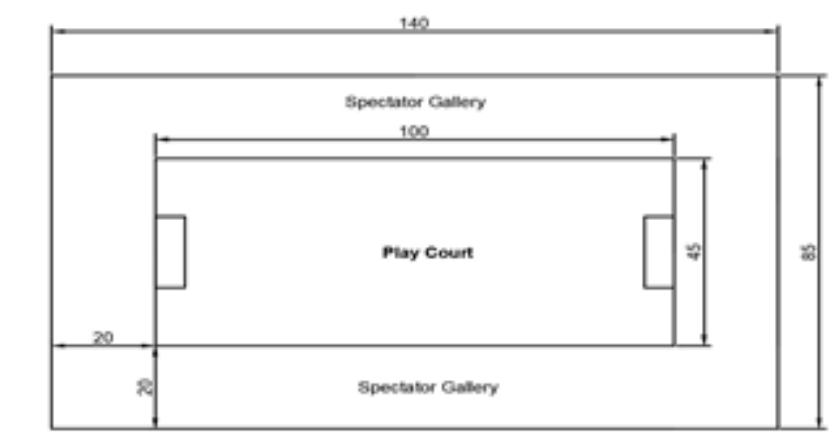

Fig 1. Plan of Football Stadium

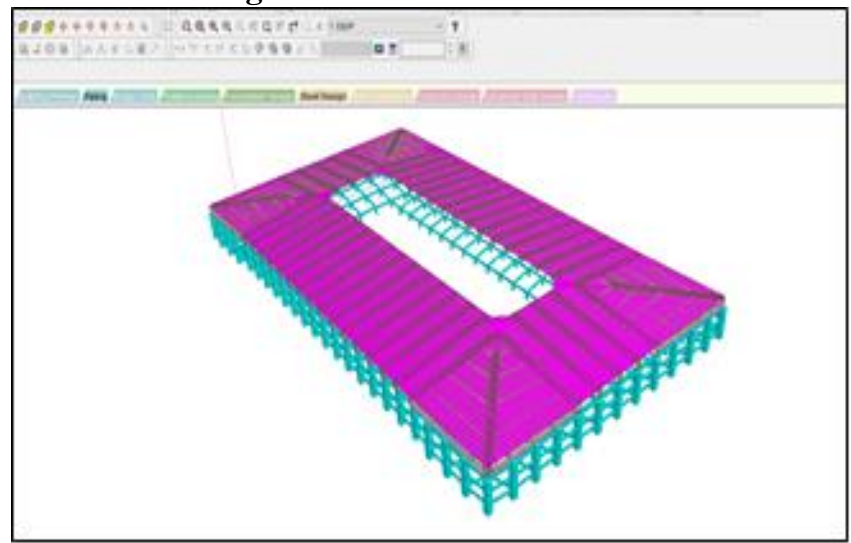

Fig 2. Model I: 3D Model of Roof Truss stadium (without shell roof covering)

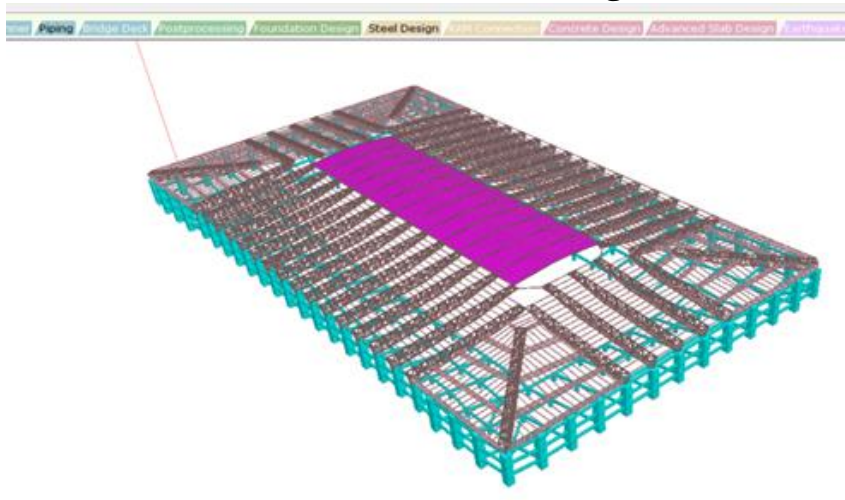

Fig 3. Model II: 3D Model of Roof Truss stadium (with shell roof covering)

\section{PReparation for ANAlysis AND DESIGN CALCULATION:}

\section{A. Truss Configuration:}

A lattice truss is a structural design element used in the building industry. To give stability and support to a building, it is made up of interlaced chords that are crosslinked horizontally and diagonally. The basic structure of a tubular truss is an N-type arrangement of straight interlocking structural components. Tubular trusses are often used in constructions where top roofs, floors, and interior loads such as services and suspended ceilings are voluntarily organized of the system. A truss is essentially an N-type structure of straight structural components with corresponding dimensions.

Axial tension or compression is the primary force acting on all truss components. Analysis and design also done using Staadpro software for simulation of behavior under gravity, seismic and wind loading. A configuration which is compound of Lattice type of truss along with $\mathrm{N}$ - type truss has been used for the roof and the same has been analysed and designed.

The steel truss is designed to be simply supported on the column and the Lattice truss is analysed according to Indian requirements. For the following various parameters, the study of Lattice truss is done on the basis of applicable Indian Standards:

\section{B. Geometry of Roof Truss:}

Roof truss $=$ Lattice Truss

Span of Truss $=32.14 \mathrm{~m}$

Spacing of Truss $=6.67 \mathrm{~m}$

\section{Shape and Dimensions of a single Lattice Roof Truss:}

The Shape of the proposed Lattice truss and Dimension is show in Fig 4 and 5 respectively

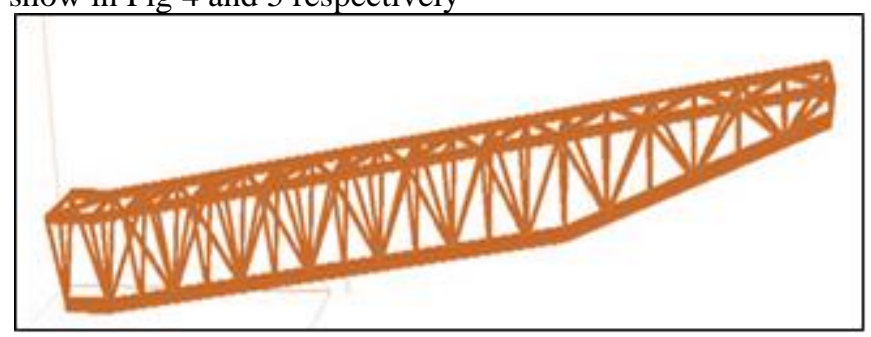

Fig 4. Shape of Lattice Truss

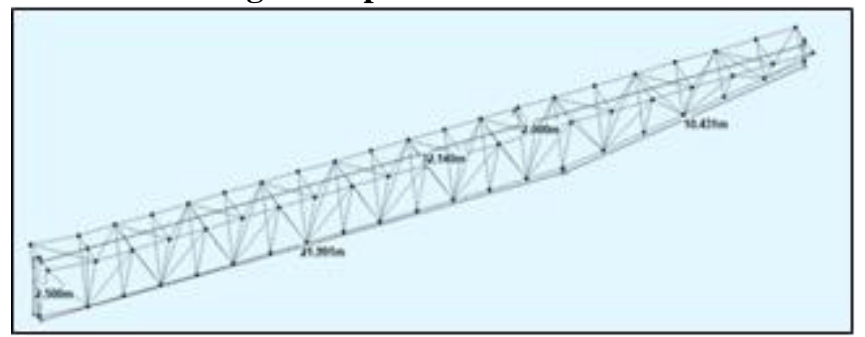

Fig 5. Dimensions of Lattice Truss

\section{Assigning of Section Properties:}

The section properties are assigned using Staad for the single lattice roof truss for both the Models which is given in Table I and Table II respectively, and the assigning of the property to Top chord, Intermediate Chord, Bottom Chord and Purlin are shown.

Table I. Section properties of Truss members (Model-I)

\begin{tabular}{|c|c|c|c|}
\hline \multicolumn{4}{|c|}{ Model-I (Stadium without Shell roof) } \\
\hline Member & Material & Section & Thickness \\
\hline Top Chord & Steel & PIP $200 \mathrm{H}$ & $6 \mathrm{~mm}$ \\
\hline $\begin{array}{c}\text { Intermediate } \\
\text { Chord }\end{array}$ & Steel & PIP $150 \mathrm{H}$ & $6 \mathrm{~mm}$ \\
\hline $\begin{array}{c}\text { Bottom } \\
\text { Chord }\end{array}$ & Steel & PIP $250 \mathrm{H}$ & $8 \mathrm{~mm}$ \\
\hline Purlin & Steel & $\begin{array}{c}\text { TUB } \\
1001005\end{array}$ & $5 \mathrm{~mm}$ \\
\hline \multicolumn{4}{|c|}{} \\
\hline Column & Concrete & $1500 \mathrm{~mm} \times 1500 \mathrm{~mm}$ \\
\hline Beam & Concrete & $300 \mathrm{~mm} \times 600 \mathrm{~mm}$ \\
\hline
\end{tabular}

Published By:

Blue Eyes Intelligence Engineering and Sciences Publication (BEIESP) 
Analysis and Design of Stadium with Truss System and Shell Roof Subjected to Wind and Seismic Loading

Table II Section properties of Truss members (Model-II)

\begin{tabular}{|c|c|c|c|}
\hline \multicolumn{4}{|c|}{ Model-II (Stadium with Shell roof) } \\
\hline Member & Material & Section & Thickness \\
\hline Top Chord & Steel & PIP $250 \mathrm{H}$ & $6 \mathrm{~mm}$ \\
\hline $\begin{array}{c}\text { Intermediate } \\
\text { Chord }\end{array}$ & Steel & PIP $150 \mathrm{H}$ & $6 \mathrm{~mm}$ \\
\hline $\begin{array}{c}\text { Bottom } \\
\text { Chord }\end{array}$ & Steel & PIP $350 \mathrm{H}$ & $8 \mathrm{~mm}$ \\
\hline Purlin & Steel & $\begin{array}{c}\text { TUB } \\
1001005\end{array}$ & $5 \mathrm{~mm}$ \\
\hline \multicolumn{4}{|c|}{} \\
\hline Column & Concrete & $1500 \mathrm{~mm} \times 1500 \mathrm{~mm}$ \\
\hline Beam & Concrete & $300 \mathrm{~mm} \times 600 \mathrm{~mm}$ \\
\hline
\end{tabular}

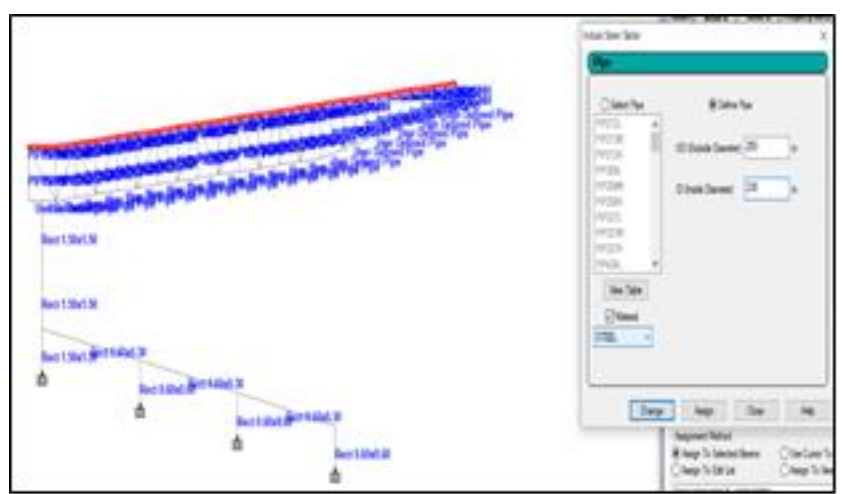

Fig.6 Assigning the section properties for Top Chord

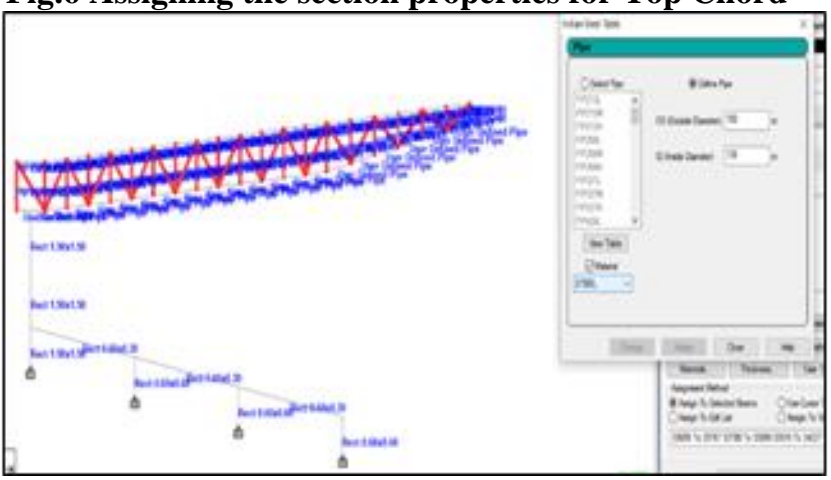

Fig.7 Assigning the section properties for Intermediate Chord

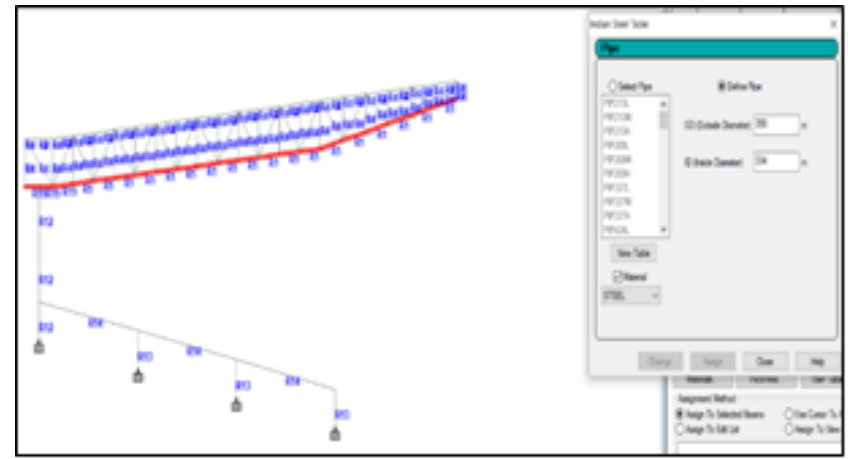

Fig.8 Assigning the section properties for Bottom Chord

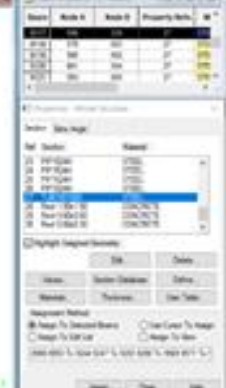

Fig.9 Assigning the section properties for Purlin The RCC Component such as Column and Beam property are shown in the below Fig 10 and 11 respectively

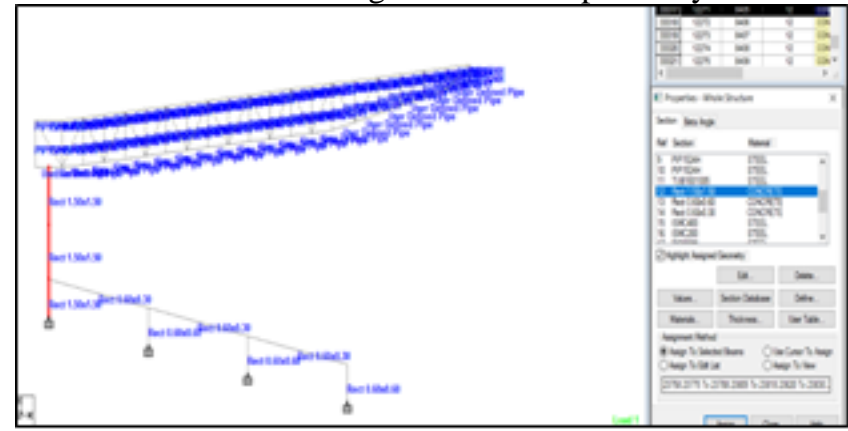

Fig.10 Assigning the properties for RCC Column

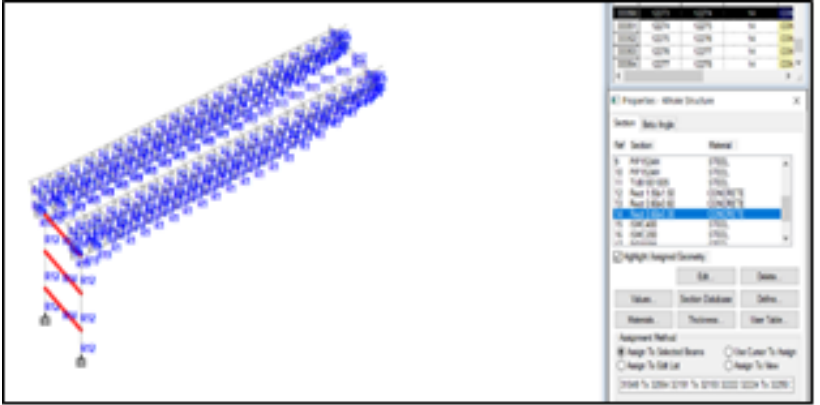

Fig.11 Assigning the properties for RCC Beam

E. Shell Roof Truss Configuration:

The typical Shell roof truss is shown in the below Fig 12 and the section properties of the same is tabulated in underneath Table III

\section{F. Geometry of Shell Roof Truss:}

Span of Truss $=25 \mathrm{~m}$.

Spacing of Truss $=6.67 \mathrm{~m}$

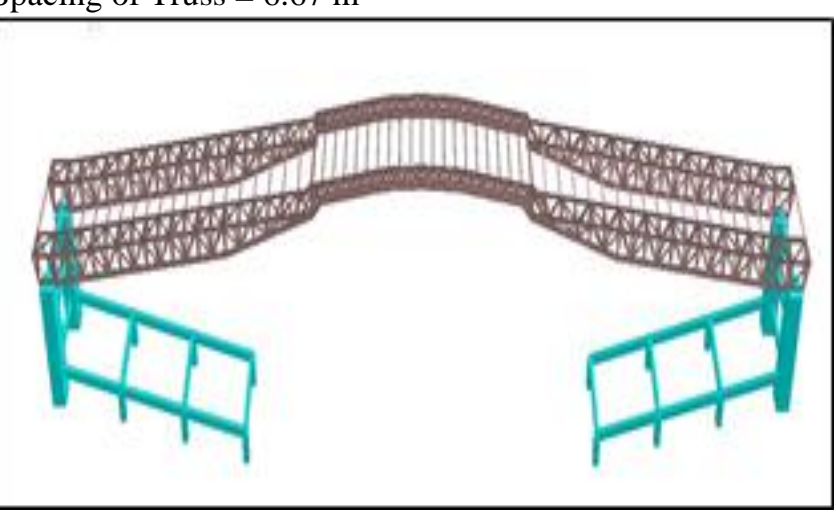

Fig.12 Typical Shell Roof Truss

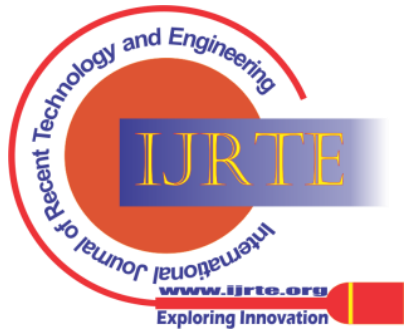


Table III Section properties of Shell Roof Truss members

\begin{tabular}{|c|c|c|}
\hline \multicolumn{3}{|c|}{ Model-II (Stadium with Shell roof) } \\
\hline Member & Material & Section \\
\hline Top Chord & Steel & $\begin{array}{c}\text { PIP 2191 } \\
\text { H }\end{array}$ \\
\hline $\begin{array}{c}\text { Intermediate } \\
\text { Chord }\end{array}$ & Steel & $\begin{array}{c}\text { PIP 1524 } \\
\text { H }\end{array}$ \\
\hline $\begin{array}{c}\text { Bottom } \\
\text { Chord }\end{array}$ & Steel & $\begin{array}{c}\text { PIP 2191 } \\
\text { H }\end{array}$ \\
\hline Purlin & Steel & $\begin{array}{c}\text { TUB } \\
90905\end{array}$ \\
\hline
\end{tabular}

\section{G. Loading:}

1. Deäd Loads:

Dead loads considering of the weight of all material and fixed components incorporated into the stadium structure, as per IS:875 (Part-I) -1987 has been considered to calculate dead load.

Live loảds are calculated às per IS:875 (Part-II) -1987 shall be the maximum loäds normal by the intended use or utilized. They may be considering the tentative load taken in fully or partially in place in roof area or not present at every time.

Calculation of Live Load on Truss member:

As per clause 4.1 Table 2 of IS: 875 (part 2)-1987

$\theta=5.33^{\circ}$

Live load on truss $=0.75 \mathrm{kN} / \mathrm{m} 2>0.4 \mathrm{kN} / \mathrm{m} 2$

\section{Wind Loads:}

The calculation of wind design force is taken as per IS:875 (Part III)- 2015.

\section{Calculation of Wind Load:}

As per clause 5.3 of IS875 (Part 3)- 2015, we have

$$
\mathrm{Vz}=\mathrm{Vb} \times \mathrm{k} 1 \times \mathrm{k} 2 \times \mathrm{k} 3
$$

Wind Zone $=$ II

Basic wind speed value $\mathrm{Vb}=39 \mathrm{~m} / \mathrm{s}$

$$
\begin{aligned}
& \mathrm{K} 1=1.06 \\
& \mathrm{~K} 2=0.97 \\
& \mathrm{~K} 3=1
\end{aligned}
$$

Design wind speed $(\mathrm{Vz})=\mathrm{Vb} \times \mathrm{k} 1 \mathrm{x} \mathrm{k} 2 \mathrm{x} \mathrm{k} 3$

$$
\begin{aligned}
& =39 \times 1.06 \times 0.97 \times 1 \\
& =40.09 \mathrm{~m} / \mathrm{s}
\end{aligned}
$$

Calculation of Wind Pressure:

Wind pressure pz is calculated by using the formula as per 5.4 of IS 875: 2015 (Part-III)

$$
\begin{aligned}
\mathrm{pz} & =0.6 \mathrm{Vz}^{\wedge} 2 \\
& =0.6 \times(40.09) \wedge 2=964.32 \mathrm{~N} / \mathrm{sq} . \mathrm{m} \\
& =0.964 \mathrm{kN} / \mathrm{sq} . \mathrm{m}
\end{aligned}
$$

\section{Calculation of Design Wind Pressure:}

$$
\begin{aligned}
\mathrm{Pd}= & \mathrm{K} \mathrm{d} \times \mathrm{K} \mathrm{a} \times \mathrm{K} \mathrm{C} \times \mathrm{pz} \\
& \mathrm{K} \mathrm{d}=0.90 \\
& \mathrm{~K} \mathrm{a}=0.92 \\
& \mathrm{~K} \mathrm{c}=0.9 \\
\mathrm{pd}= & \mathrm{K} \mathrm{d} \times \mathrm{K} \mathrm{a} \times \mathrm{K} \mathrm{c} \times \mathrm{pz} \\
= & 0.9 \times 0.92 \times 0.9 \times 0.964 \\
= & 0.718 \mathrm{kN} / \mathrm{m} 2
\end{aligned}
$$

Design wind pressure shall not be less than $0.7 \times \mathrm{Pz}$

$=0.7 \times 0.964$

$=0.674 \mathrm{kN} / \mathrm{sq} \cdot \mathrm{m}$

\section{Live Loàds:}

0.718 kN/sq.m > 0.674 kN/sq.m Hence OK

Calculation of Wind Pressure Coefficients:

$$
\mathrm{F}=(\text { Cpe }- \text { Cpi). A. pd }
$$

\section{Calculation of External Pressure Coefficients:}

Let $\theta$ be the inclination of the roof $(\theta)$

$\operatorname{Tan}(\theta)=$ rise $/$ half of span

$$
\operatorname{Tan}(\theta)=3 /(32.14)
$$

$\theta=5.33$

$\mathrm{h}=19.5 \mathrm{~m}, \mathrm{w}=85 \mathrm{~m}$

$\mathrm{h} / \mathrm{w}=19.5 / 85$

$=0.22<0.5$

Cpe condition $\mathrm{h} / \mathrm{w}<1 / 2$

Table IV External Pressure Coefficients

\begin{tabular}{|c|c|c|c|}
\hline \multicolumn{3}{|c|}{ Cpe } \\
\hline \multicolumn{2}{|c|}{ Wind angle $=\mathbf{0}^{\circ}$} & \multicolumn{2}{c|}{ Wind angle $=\mathbf{9 0}^{\circ}$} \\
\hline $\mathrm{EF}$ & $\mathrm{GH}$ & $\mathrm{EG}$ & $\mathrm{FH}$ \\
\hline-0.91 & -0.4 & -0.8 & -0.41 \\
\hline
\end{tabular}

Calculation of Internal Pressure Coefficients:

Structures with openings larger than $20 \%$ the value of internal pressure coefficient is taken as Cpi $=+0.7$ and -0.7

Table V Wind Load calculation

\begin{tabular}{|l|l|c|c|c|}
\hline \multicolumn{3}{|c|}{ Wind angle } & \multicolumn{2}{c|}{ Total pressure $=($ Cpe - Cpi) pz } \\
\hline \multirow{2}{|c|}{} & Cpe & Cpi $=+\mathbf{0 . 7}$ & Cpi $=-\mathbf{0 . 7}$ \\
\hline $0^{\circ}$ & Windward & -0.91 & $-1.5424 \mathrm{kN} / \mathrm{m} 2$ & $-0.1928 \mathrm{kN} / \mathrm{m} 2$ \\
\cline { 2 - 5 } & Leeward & -0.4 & $-1.0604 \mathrm{kN} / \mathrm{m} 2$ & $0.289 \mathrm{kN} / \mathrm{m} 2$ \\
\hline $\begin{array}{l}90 \\
0\end{array}$ & Windward & -0.8 & $-1.446 \mathrm{kN} / \mathrm{m} 2$ & $-0.0964 \mathrm{kN} / \mathrm{m} 2$ \\
\cline { 2 - 5 } & Leeward & -0.41 & $-1.0604 \mathrm{kN} / \mathrm{m} 2$ & $0.2892 \mathrm{kN} / \mathrm{m} 2$ \\
\hline
\end{tabular}

Maximum wind load in Windward direction $=-1.5424$ $\mathrm{kN} / \mathrm{m} 2$ and Maximum wind load in Leeward direction = $1.0604 \mathrm{kN} / \mathrm{m} 2$ where, (-) indicates uplift pressure also called as Suction. The action of wind on Windward and Leeward face of the structure in both $\mathrm{X}$ and $\mathrm{Z}$ direction is șhown in Fig 13, 14, 15 and 16 respectively.

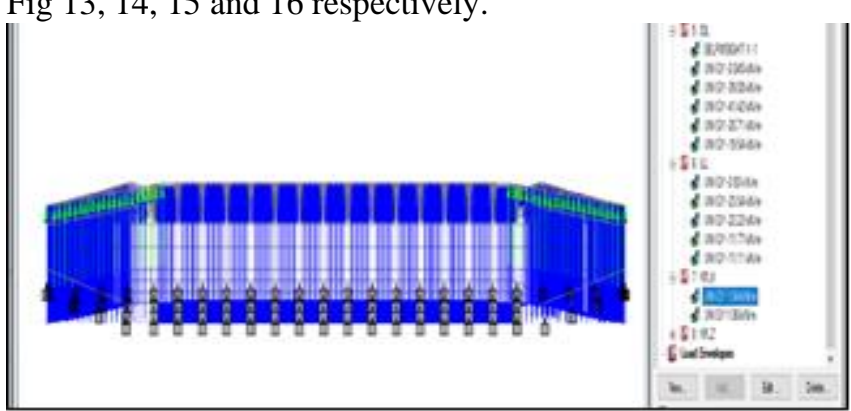

Fig.13 Wind Load acting on Windward face X direction

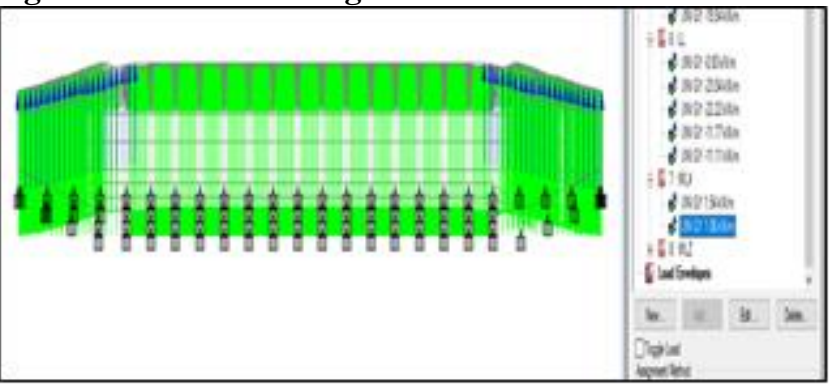

Fig.14 Wind Load acting on Leeward face $\mathrm{X}$ direction

Published By:

Blue Eyes Intelligence Engineering and Sciences Publication (BEIESP)

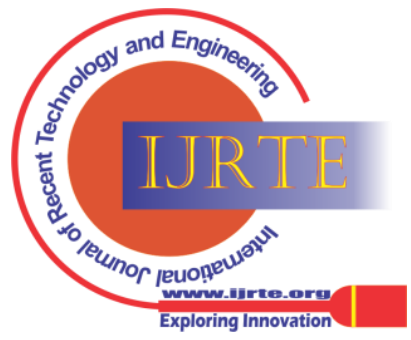




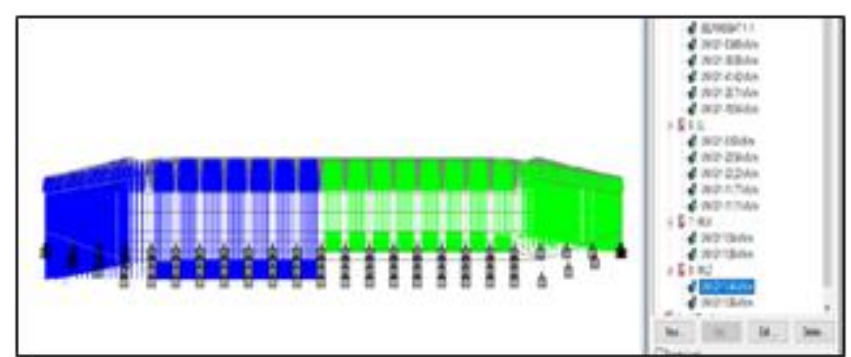

Fig.15 Wind Load acting on Windward face $\mathrm{Z}$ direction

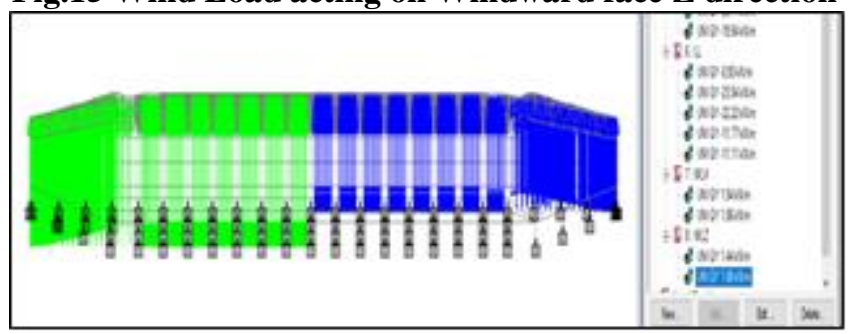

Fig.16 Wind Load acting on Leeward face $Z$ direction

\section{Seismic Load:}

In accordance with IS1893-2016 (part I) the parameters used for Seismic analysis of the structure are given in the Table VI. The action of earthquake load in $\mathrm{X}+, \mathrm{X}-, \mathrm{Z}+$ \& $\mathrm{Z}-$ is shown in fig 17, 18, 19 and 20 respectively.

Table VI: Parameters for Seismic analysis

\begin{tabular}{|l|l|}
\hline Earthquáke Zone & IV \\
\hline Zone fäctor (Z) & 0.36 \\
\hline ResponȘe Reduction Fảctor (R) & 5 (S.M.R.F.) \\
\hline Importance Factor (I) & 1.5 (Very Important Building) \\
\hline Soil Type & II (Medium Soil) \\
\hline Type of Structure & I \\
\hline Diaphragm Damping for steel & $2 \%$ \\
\hline $\begin{array}{l}\text { Diaphragm Damping for } \\
\text { concrete }\end{array}$ & $5 \%$ \\
\hline
\end{tabular}

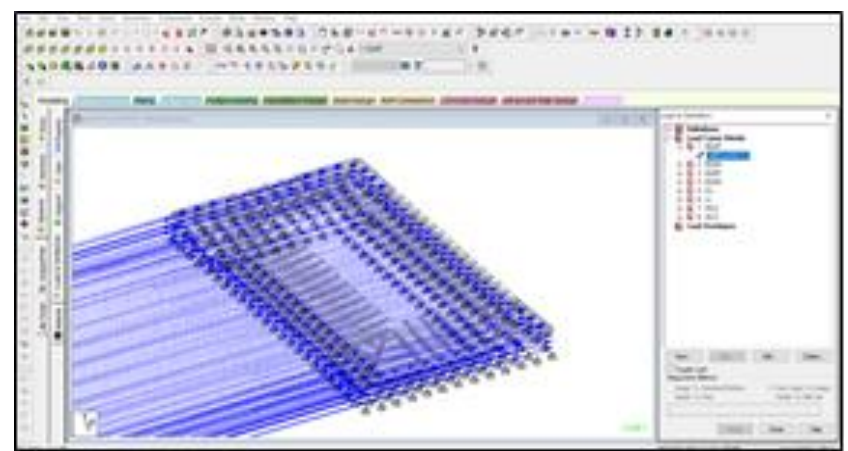

Fig.17 Seismic Load acting on structure in $\mathrm{X}+$ direction

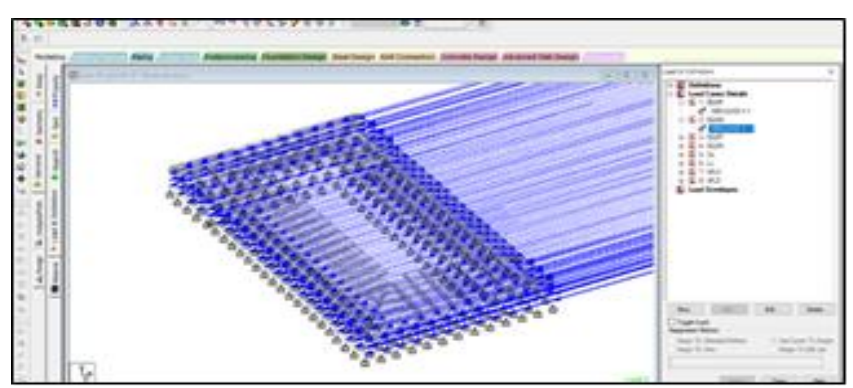

Fig.18 Seismic Load acting on structure in X- direction

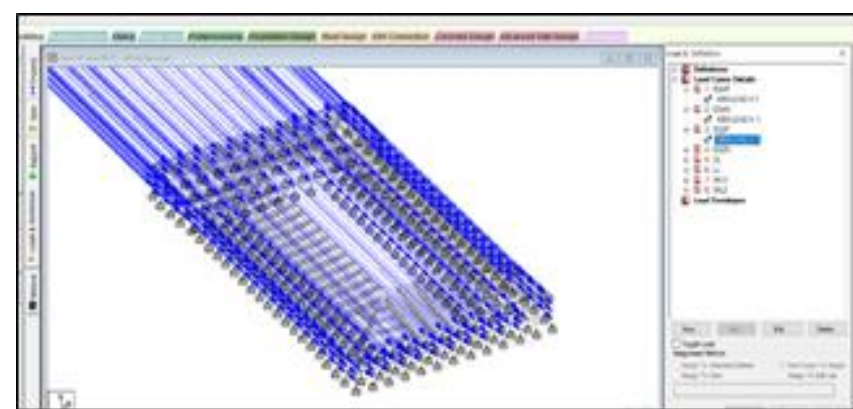

Fig.19 Seismic Load acting on structure in $\mathrm{Z}+$ direction

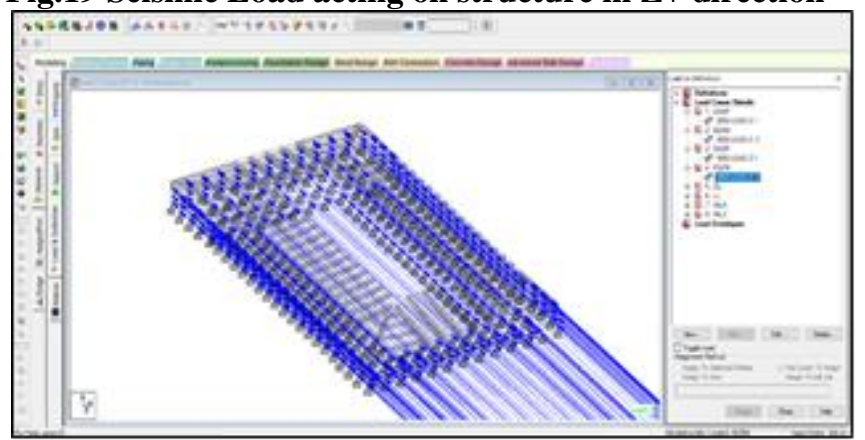

Fig.20 Seismic Load acting on structure in Z- direction After adding the Seismic load in both $\mathrm{X}$ and $\mathrm{Z}$ direction the method of seismic analysis is applied such as RSA and THA which is shown in below Fig 21 and Fig 22

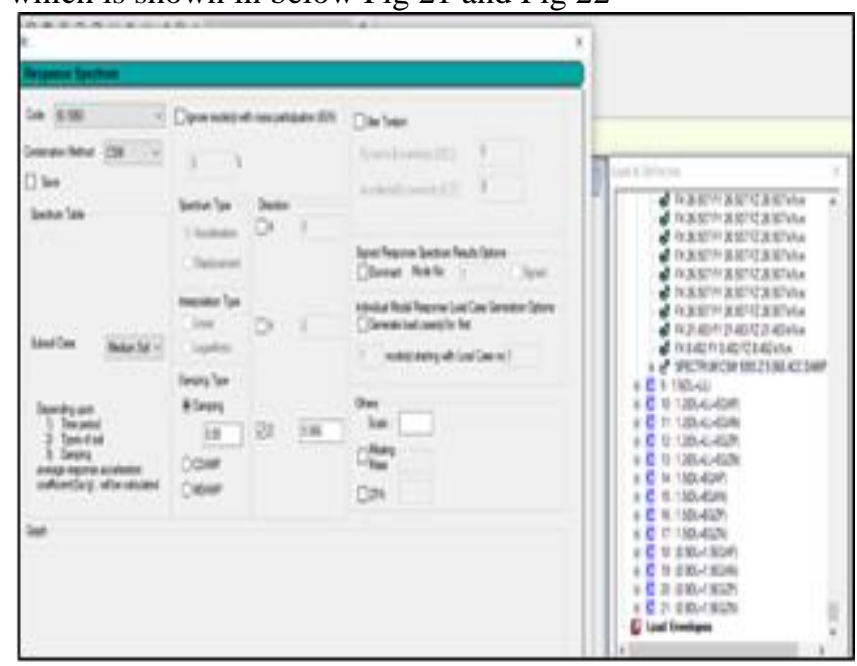

Fig.21 Response Spectrum analysis

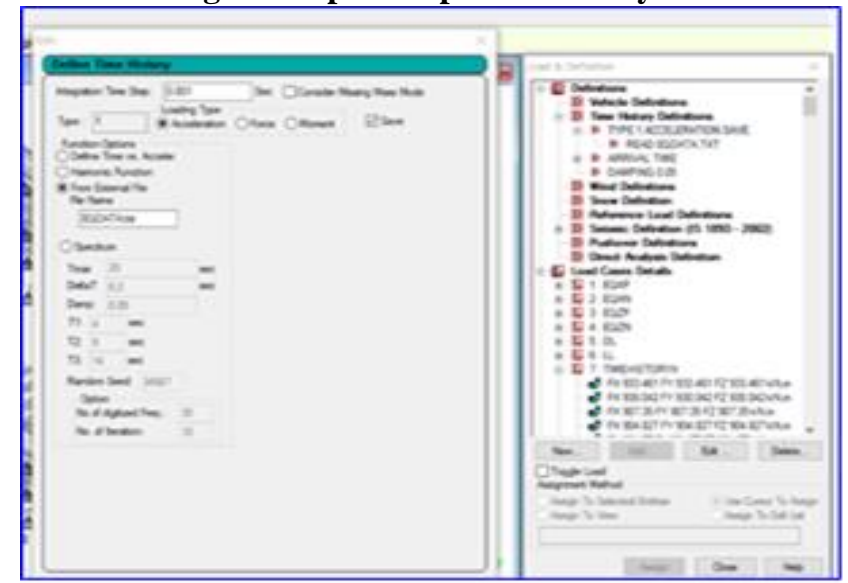

Fig.22 Time History Analysis

Published By:

Blue Eyes Intelligence Engineering and Sciences Publication (BEIESP)

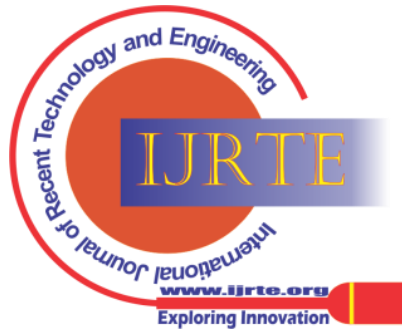


After creation of model and assigning the properties, the model has been checked and obtained zero errors is shown in the below Fig, 23. The unity check ratio has been checked for the typical steel truss members and Shell members and were in the permissible limit. The same is shown in the below Fig 24 and Fig 25.

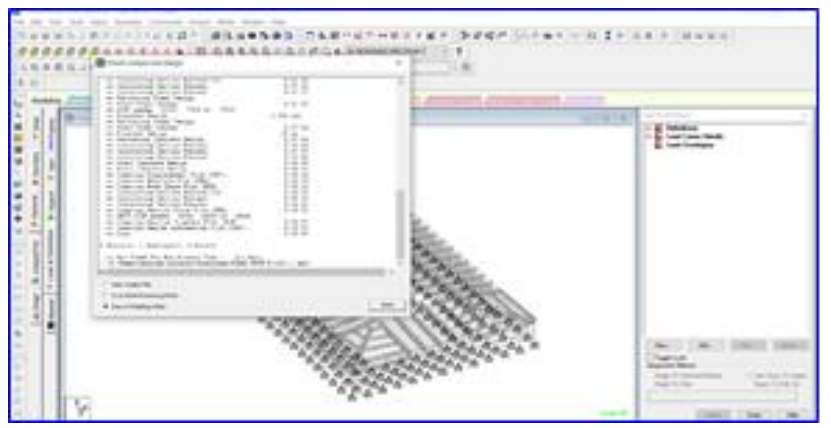

Fig,23 Checking the Model

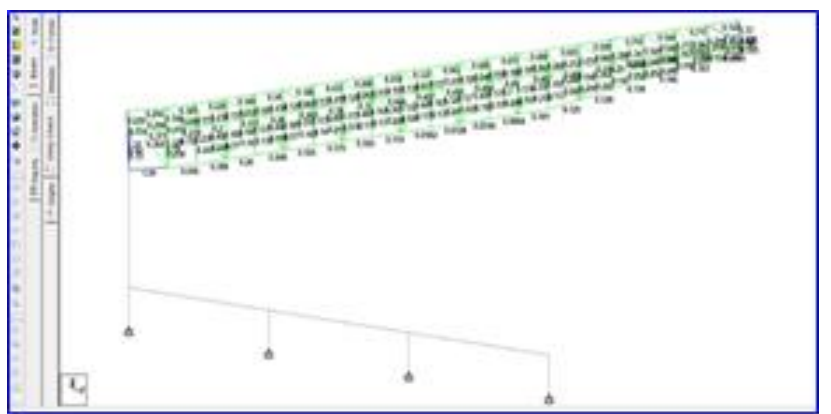

Fig.24 Unity check for safe section

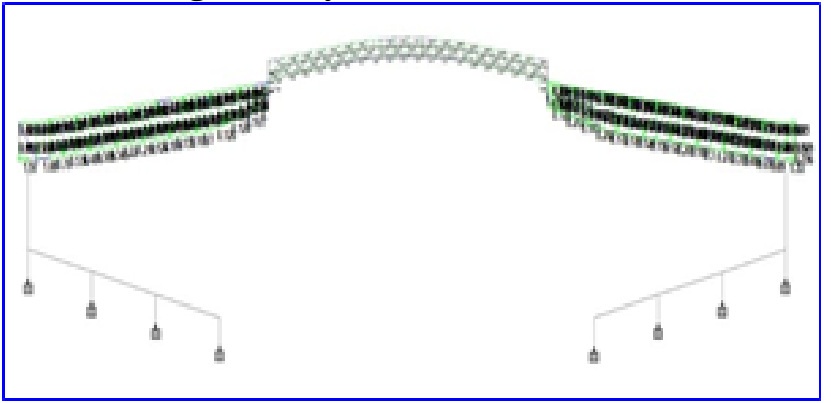

Fig.25 Unity Check for Typical Shell Roof Truss

\section{RESULTS AND DISCUSSION}

After the completion of analysis of the structure the results are extracted as stated, now these results are tabulated accordingly and the effect of various parameters are observed and discussed. This project focuses on the wind and seismic behavior on the structure hence the parameters are tabulated and are discussed. Then latter the Manual design of Beam, Column, Seating Platform, Footing and Base Plate connection is done with the help of forces obtained from Staad Analysis.

\section{A. Generalize co-ordinates in Staad.pro V8i SS6:}

As discussed, earlier Staad.pro V8i SS6uses Finite Element Method (FEM) to analyse the various unknowns in a structural system. It is necessary to understand the generalize coordinate system, with respect to which the results are generated so that the behavior of structural system can be studied. Figure 26 shows the reference axis in Staad.pro V8i SS6

The $\mathrm{X}$ and $\mathrm{Z}$ coordinates are referred as horizontal direction of the parameter, whereas the $\mathrm{Y}$ coordinates is referred as vertical direction of the parameter. These are the generalize coordinates in Staad.pro v8i SS6.

\section{B. Wind Analysis Results:}

Displacement: The Displacements due to wind load action in $\mathrm{X}$ and $\mathrm{Z}$ direction at particular nodes for both Model-I and Model-II i.e., Stadium without shell roof and with Shell roof.

The Displacement due to Wind action in X direction on both Model-I and Model-II at a particular node have been shown in Fig, 27 and Fig, 28

Fig.27 Displacement Chart due to Wind Action in X direction

From the graph at node number 5567 the displacement in Xdirection is maximum i.e., $0.018 \mathrm{~mm}$ for Model-I whereas at same node the displacement is $0.002 \mathrm{~mm}$ for Model-II. Hence the Displacement for Model-II is decreases by 88.88 $\%$ when compared to Model-I.

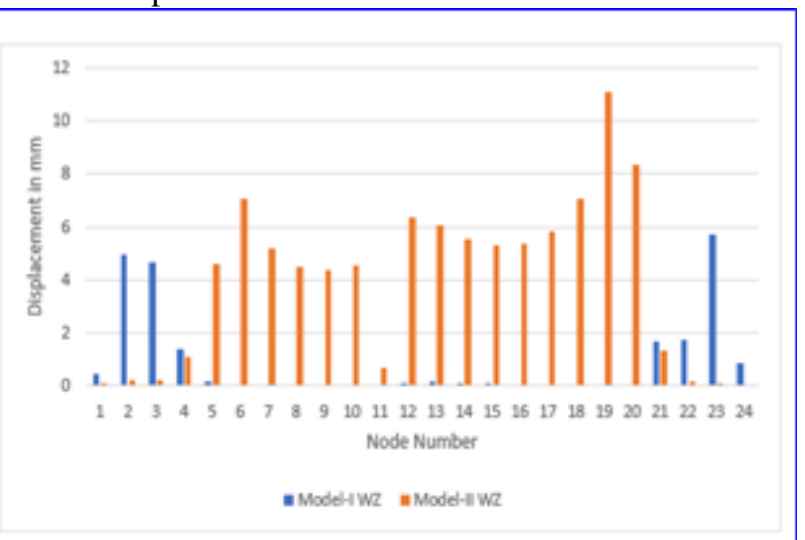

Fig.28 Displacement Chart due to Wind Action in $\mathrm{Z}$ direction 
From the graph at node number 5567 the displacement in Zdirection is $0.468 \mathrm{~mm}$ for Model-I whereas at same node the displacement is $0.107 \mathrm{~mm}$ for Model-II. Hence the Displacement for Model-II is decreases by $77.13 \%$ when compared to Model-I.

Drift: The Drift due to wind load action in $\mathrm{X}$ and $\mathrm{Z}$ direction at particular nodes for both Model-I and Model-II i.e, Stadium without shell roof and with Shell roof is shown in Fig. 29.

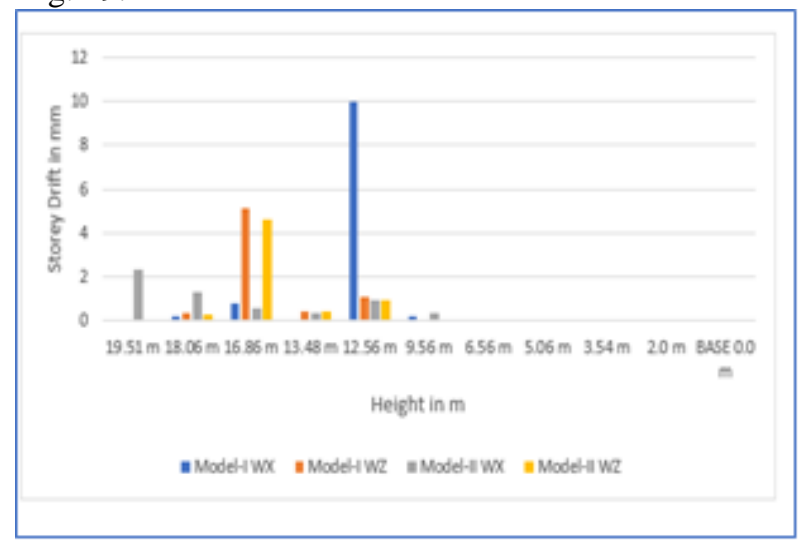

Fig.29 Story Drift Chart due to Wind action

From the graph at Height $12.56 \mathrm{~m}$ the drift in X-direction is maximum i.e., $9.981 \mathrm{~mm}$ for Model-I whereas at same Height the drift is $0.957 \mathrm{~mm}$ for Model-II. Hence the Drift for Model-II is decreases by $90.41 \%$ when compared to Model-I and from the graph at Height $12.56 \mathrm{~m}$ the drift in Z-direction is $1.112 \mathrm{~mm}$ for Model-I whereas at same Height the drift is $0.938 \mathrm{~mm}$ for Model-II. Hence the Drift for Model-II is decreases by $15.64 \%$ when compared to Model-I.

\section{Seismic Analysis Results:}

The seismic results for both models discussed are time period, base shear, displacement, story drift. These parameters are of core importance for the structure to be an earthquake resistant.

Time Period: Time period is defined as "In an earthquake it is a time required by a structure (as a whole) to complete one oscillation from its mean position". Here in STAAD in a dynamic analysis of response spectrum 6 modes of oscillation is considered in which $90 \%$ and above accuracy is achieved. It is quite obvious that, if time period is less the building will take less time to oscillate and vice versa. Less time period of a structure will imply good resistance towards an earthquake. It is only the undamped free vibration of the structure. The Fig 30 underneath speaks about the estimations of time period acquired by the investigation utilizing STAAD for Model-I and Model-II respectively

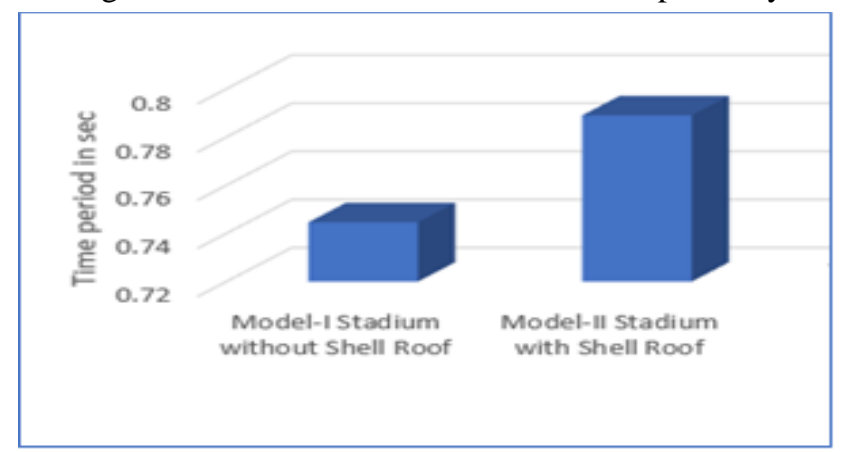

Fig.30 Time Period
From the graph it is observed that the time period for Model-I is $0.74467 \mathrm{sec}$ whereas for Model-II is $0.78906 \mathrm{sec}$, Hence the Time period for Model-II is increases by $5.12 \%$ when compared to Model-I

Design Seismic Base Shear: During a lateral ground motion, the structure gets displaced from its mean position due to the application of lateral forces at every story height the algebraic addition of these lateral forces at the base of the structure gives base shear. It should be noted that structure gets displaced in both directions hence base shear in each direction is calculated i.e., in $\mathrm{X}$ and $\mathrm{Z}$ direction in accordance with the generalize coordinate. The underneath Fig 31 demonstrates the estimations of seismic base shear of both the models, by the 2 distinctive examination techniques like, RSA, THA the base shear likewise relies on the state of the site on which the structure needs to stand.

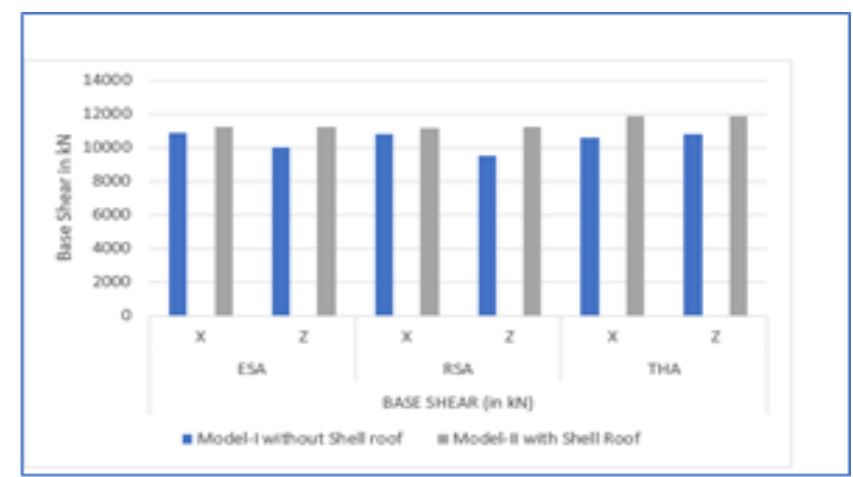

Fig.31 Base Shear

Story Drift: The results of story drift given below are due to worst load combination with partial safety factor. But the design of all structural members in STAAD have been passed in software which is for load combination with partial safety factor 1 , thus this implies that story drifts are within the limits. The story drift in $\mathrm{X}$ and $\mathrm{Z}$ directions are tabulated in underneath Fig 32 for the both models, these qualities are acquired by performing examination by various techniques utilizing STAAD.

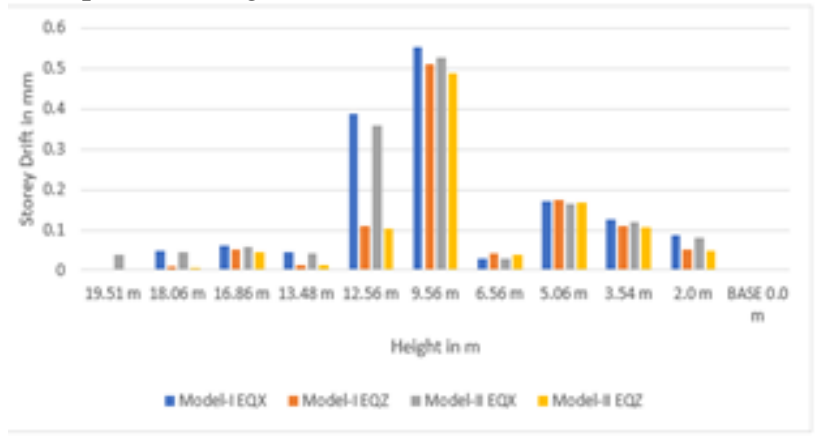

Fig.32 Story Drift Chart due to Seismic action

From the graph it is observed that the Story Drift at $9.56 \mathrm{~m}$ height due to ESA in X direction is maximum i.e., 0.551 $\mathrm{mm}$ for Model-I whereas at same Height the drift is 0.527 $\mathrm{mm}$ for Model-II. Hence the Story Drift for Model-II is decreases by $4.35 \%$ when compared to Model-I. From the graph it is observed that the Story Drift at $9.56 \mathrm{~m}$ height due to ESA in $\mathrm{Z}$ direction is maximum i.e., $0.511 \mathrm{~mm}$ for Model-I whereas at same Height the drift is $0.489 \mathrm{~mm}$ for Model-II.

Published By:

Blue Eyes Intelligence Engineering and Sciences Publication (BEIESP)

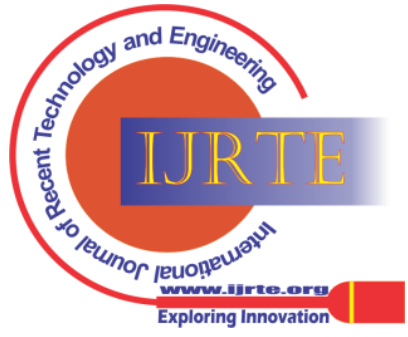


Hence the Story Drift for Model-II is decreases by $4.30 \%$ when compared to Model-I.

Displacement: During a ground motion due to lateral stiffness of the column the story is displaced with respect to ground. This lateral distance with which the floor is displaced during a ground motion of an earthquake is called story displacement. The limit is given by $\mathrm{H} / 150$ where $\mathrm{H}=$ Height of the structure as per clause 5.6.1 IS 800:2007 and within the limit. with respect to the generalize coordinate shown in Fig. 33 and Fig.34.

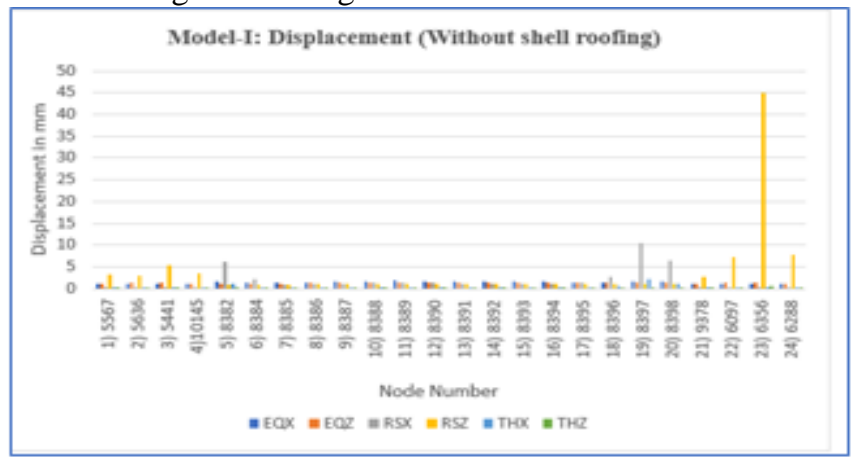

Fig.33 Displacement due to Seismic Action Model-I

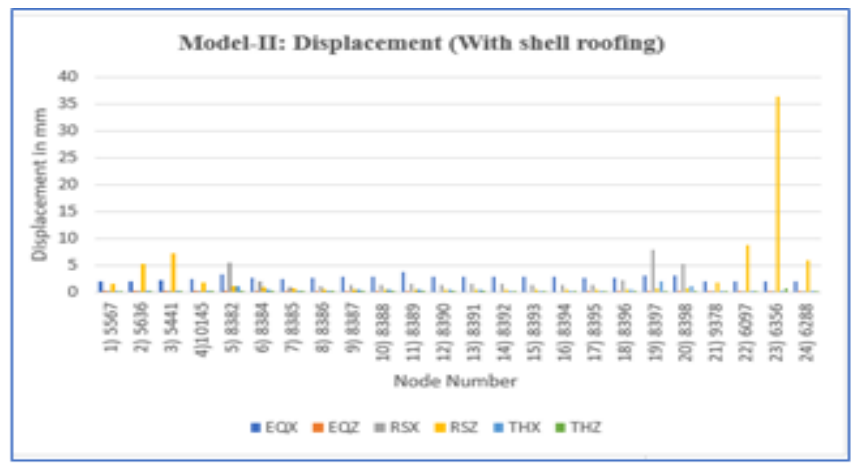

Fig.34 Displacement due to Seismic Action Model-II

From the graph at node number 6356 the Story displacement due to ESA in X-direction is $1.123 \mathrm{~mm}$ for Model-I whereas at same node the displacement is $2.049 \mathrm{~mm}$ for Model-II. Hence the Displacement for Model-II is increases by 45.19 $\%$ when compared to Model-I.

From the graph at node number 6356 the Story displacement due to ESA in Z-direction is $1.503 \mathrm{~mm}$ for Model-I whereas at same node the displacement is $0.008 \mathrm{~mm}$ for Model-II. Hence the Displacement for Model-II is decreases by 99.46 \% when compared to Model-I.

Also, from the graph it is observed that at the same node Story displacement due to RSA and THA in X direction for Model-II is decreases by $18.87 \%$ and increases by $8.33 \%$, respectively when compared to Model-I.

From the graph it is observed that at the same node Story displacement due to RSA and THA in Z direction for Model-II is decreases by $19.19 \%$ and $9.61 \%$ respectively when compared to Model-I

\section{DESIGNS:}

The design of structural components such as Beam, Column, Seating Platform Slab, Footing and Base Plate Connection is carried out and discussed below.

\section{Design of RC Beam:} all the obtained results for Model-I and Model-II were

Typical design details of RC Beam with No 32871 shown in Fig. 35 are presented in this section

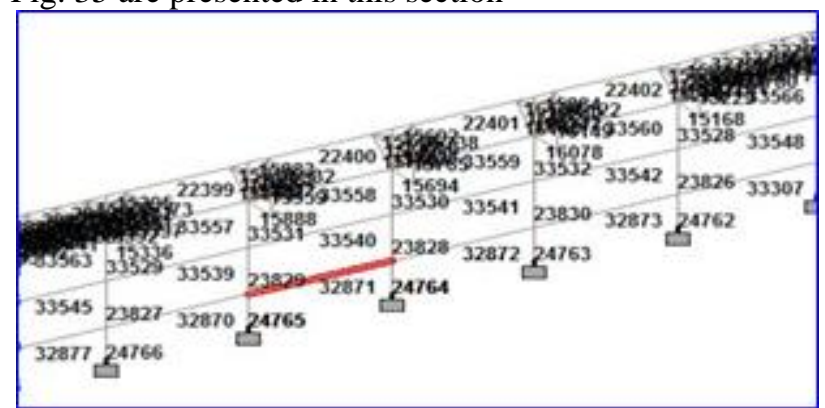

Fig. 35 RC Beam Number 32871

Beam Section provided (300 x 600)

$\mathrm{Fck}=30 \mathrm{Mpa}$

Fy $=500 \mathrm{Mpa}$

Forces from Staad

Max support Moment $=255 \mathrm{kNm}$

Mid span moment $=127 \mathrm{kNm}$

shear force $=205 \mathrm{KN}$

The Shear force and Bending Moment diagrams are shown in Fig. 36 \& 37 respectively. The design details of the beam are given in Fig 38.

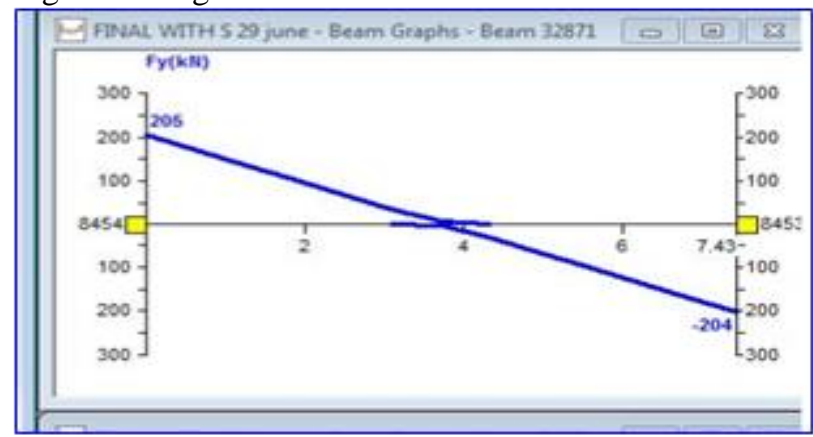

Fig. 36 Shear force diagram for Beam 32871
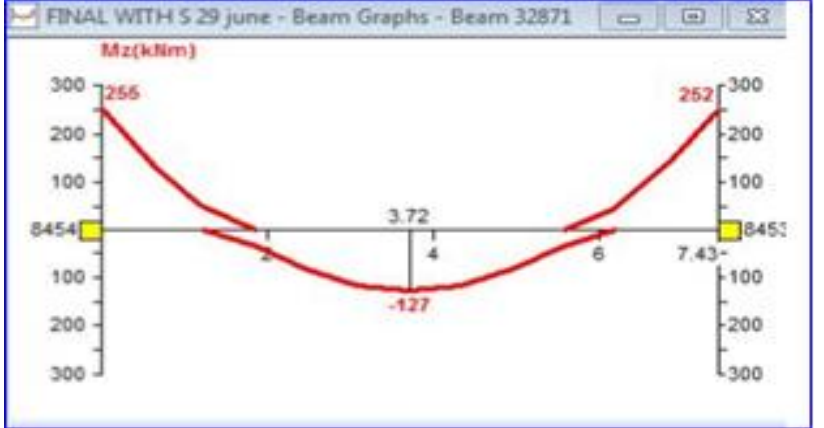

Fig. 37 Bending moment diagram for Beam 32871

\begin{tabular}{|c|c|c|c|c|c|c|c|c|c|c|c|}
\hline \multicolumn{12}{|c|}{ 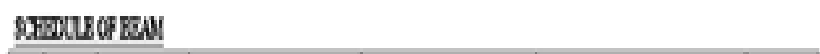 } \\
\hline \multirow{2}{*}{$\begin{array}{l}2 \\
105\end{array}$} & \multirow{2}{*}{$\begin{array}{l}\text { WN } \\
\text { WO }\end{array}$} & \multirow{2}{*}{$\begin{array}{l}800808 \\
(B \times 0)\end{array}$} & \multicolumn{2}{|c|}{ 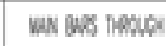 } & \multicolumn{2}{|c|}{ pras bus } & \multicolumn{4}{|c|}{ STRM } & \multirow{3}{*}{ RTWOS } \\
\hline & & & Sonto Mus & 100 316 & of Vo & of ${ }_{0}^{\circ}$ & & si & & $\pi / 2$ & \\
\hline \multirow{2}{*}{\multicolumn{2}{|c|}{ 1. $\beta=1$}} & \multirow[b]{2}{*}{$30 \times 60$} & II & II & 2 & 8 & Dh & PING & & WOE & \\
\hline & & & $1-280$ & $+\infty \mathrm{N}$ & $=$ & $3+84$ & 16 & $0136 \mathrm{C} / \mathrm{K}$ & 7 & 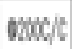 & $2-15000$ \\
\hline 2 & $18 \cdot 1$ & 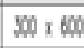 & $3-16$ & $3-10$ & $+\cdots$ & 516 & 86 & $0100 / \mathrm{T}$ & 80 & $0130, / 6$ & 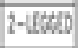 \\
\hline
\end{tabular}

Published By:

Blue Eyes Intelligence Engineering and Sciences Publication (BEIESP)

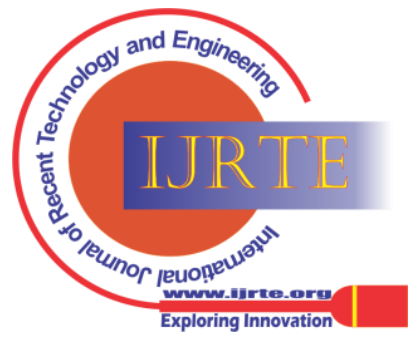




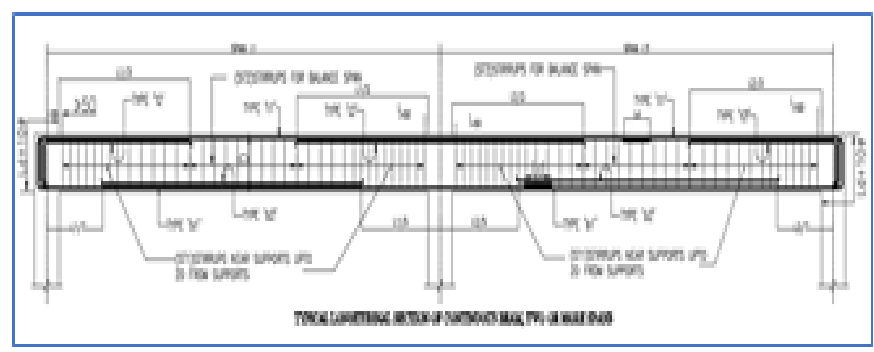

Fig.38 Reinforcement Details of Beam section

\section{Design of Column:}

Typical design details of RC Column with No 24765 shown in Fig. 39 Axial force and BM values are shown in Fig 40 and are presented in this section

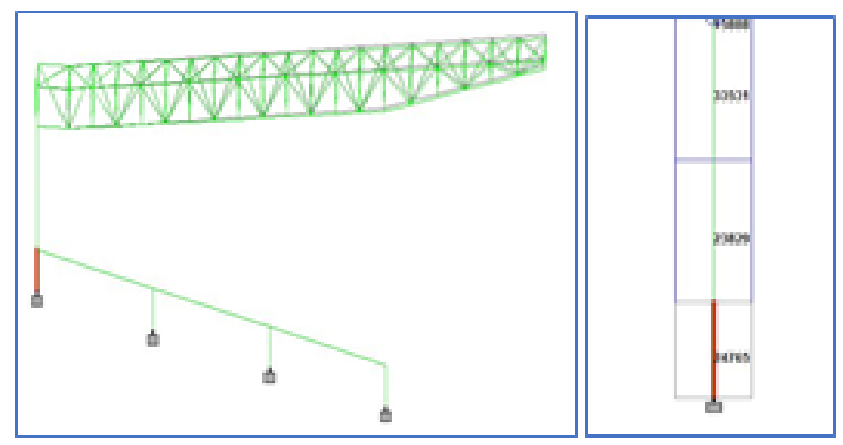

Fig.39 RC Column 24765

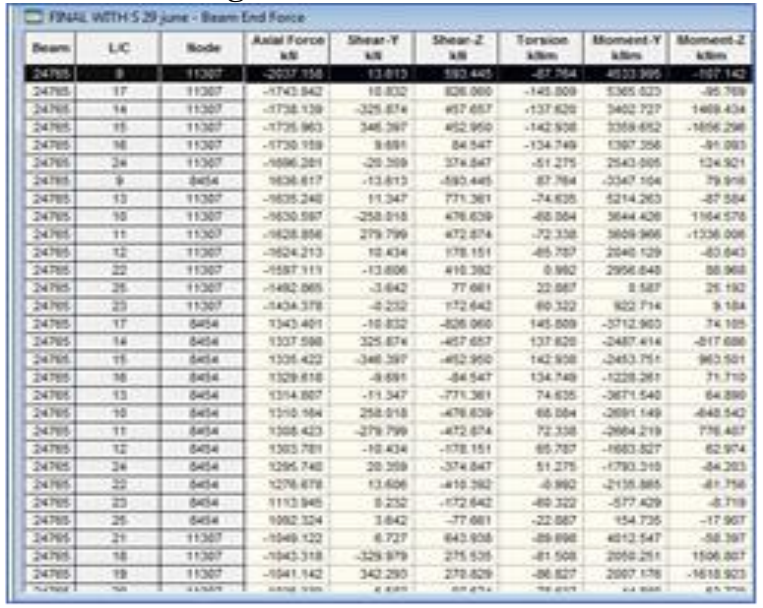

Fig.40 Axial force and BM values for Column 24765

\section{Forces from Staad}

Column Dimension $=1500 \mathrm{~mm} \times 1500 \mathrm{~mm}$

Grade of concrete $=30 \mathrm{~N} / \mathrm{mm} 2$

Charäcteristic strength of reinforcement $=500 \mathrm{~N} / \mathrm{mm} 2$

The design details of the Column is given in Fig 41 .

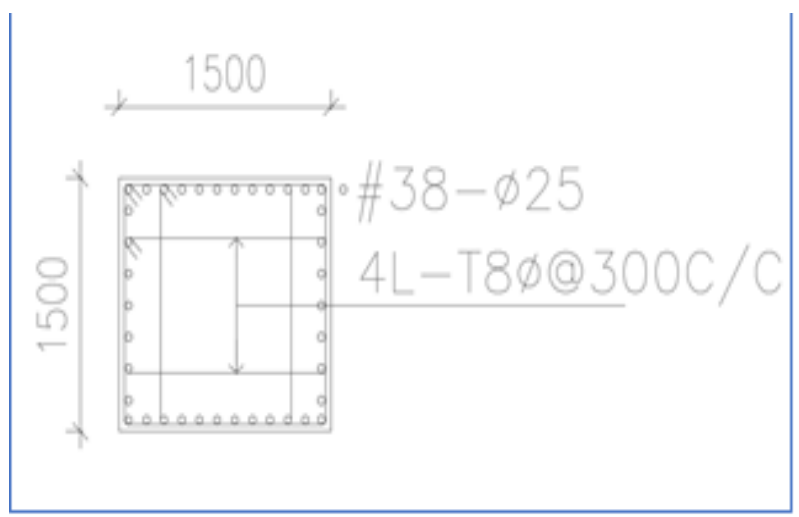

Fig.41 Reinforcement Details of Column section

Retrieval Number: 100.1/ijrte.C64190910321

DOI: 10.35940/ijrte.C6419.0910321

Journal Website: www.ijrte.org

\section{Design of Footing:}

Design of Isolated footing:

Forces from Staad:

Axial Force $1756.305 \mathrm{kN}$

Moment in $\mathrm{X}$ direction $=5.415 \mathrm{kNm}$

Moment in $\mathrm{Z}$ direction $=1701.74 \mathrm{kNm}$

$\mathrm{P}=1170.87 \mathrm{KN}$

$\mathrm{SBC}=220 \mathrm{kN} / \mathrm{m} 2$

$\mathrm{SBC}=220 \times 1.25=275 \mathrm{kN} / \mathrm{m} 2$

Column size $=1500 \mathrm{~mm} \times 1500 \mathrm{~mm}$

Area of Footing

$\mathrm{A}=($ Total load $) / \mathrm{SBC}=(1170.87 * 1.1) / 275=4.68 \mathrm{~m}^{\wedge} 2$

Provide Square Footing of Size $=\sqrt{ } 4.68=2.16 \mathrm{~m}$

Provided area $=3.5 \mathrm{~m} \times 5 \mathrm{~m}$

The design details of the isolated footing is given in Fig 42.

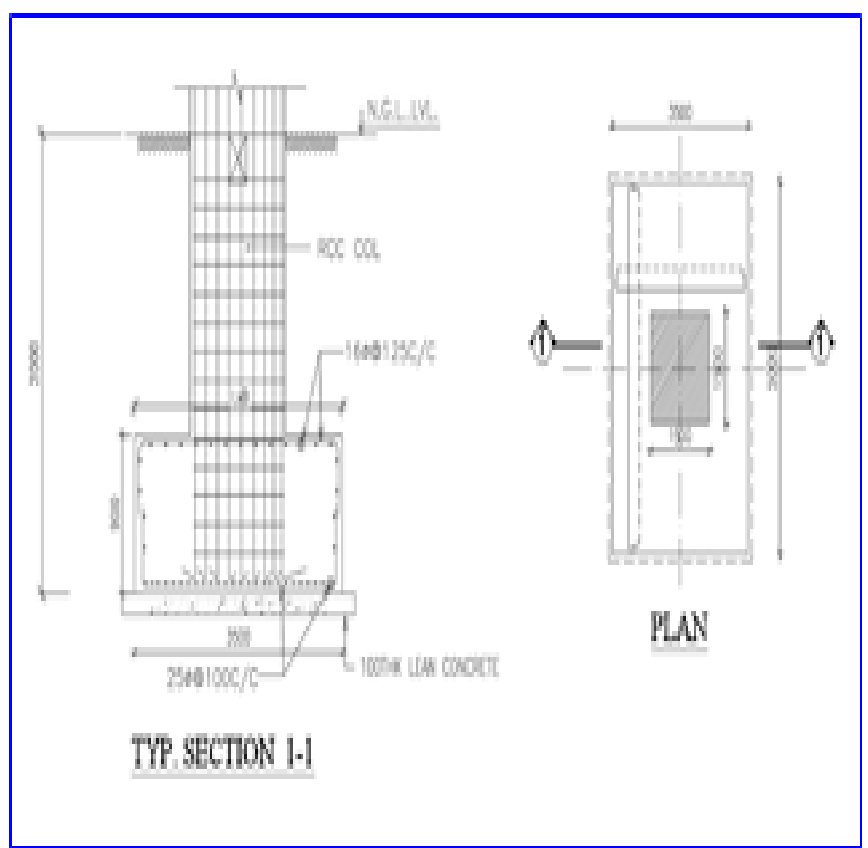

Fig.42 Footing Details

\section{Design of Seating Platform Slab:}

The Seating Platform is a huge structure designed to carry the superimposed load of furniture and audience. The furniture is arranged on a number of successive steps so that view of the audience is not obstructed. These steps along with the waist slab are supported on rackers which on turn are supported on wall on one side and the fulcrum girder on the other side. The treads are normally kept between 900 to $1100 \mathrm{~mm}$ and the risers between 100 to $125 \mathrm{~mm}$. The superimposed load may vary between 4 to $5 \mathrm{kN} / \mathrm{m}^{\wedge} 2$.The General Layout of Seating Platform is shown in the Fig.43 Live Load inclusive of furniture $5 \mathrm{kN} / \mathrm{m}^{\wedge} 2$.

Horizontal tread $=1 \mathrm{~m}$

Rise $=120 \mathrm{~mm}$

The depth of fulcrum girder $=1 \mathrm{~m}$.

Width of Gangway $=1 \mathrm{~m}$

Density of Concrete $=25 \mathrm{kN} / \mathrm{m}^{\wedge} 3$

Published By:

Blue Eyes Intelligence Engineering and Sciences Publication (BEIESP)

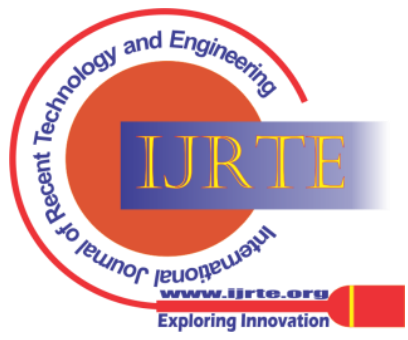




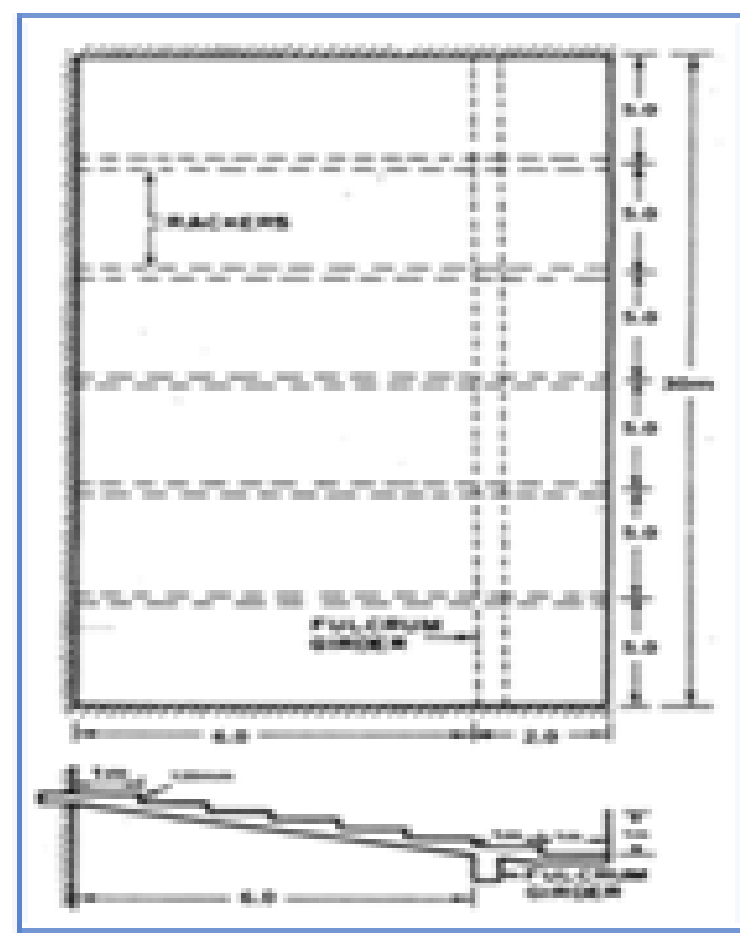

Fig.43 General Layout of Seating Platform

Loading on Racker Beam, SFD and BMD is shown in the below Fig 44

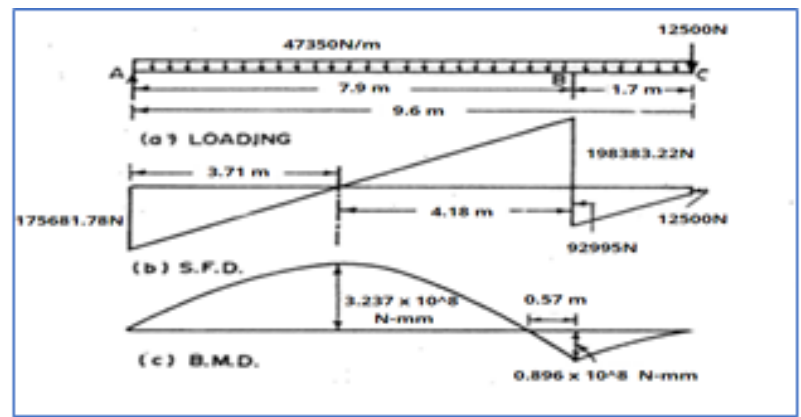

Fig. 44 Loading on Racker Beam, SFD and BMD

The reinforcement details of the T beam is given in Fig.45

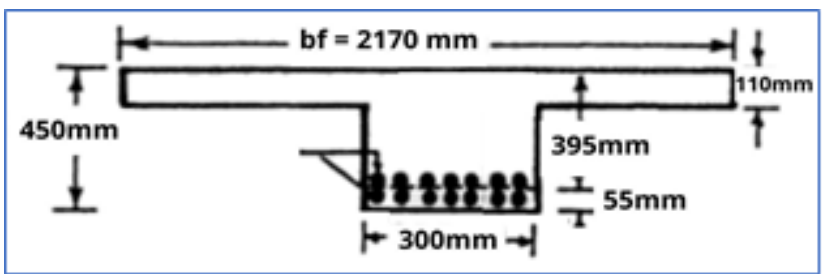

Fig.45 Reinforcement Details of T-Beam

The details of reinforcement of Seating Platform are shown in Fig. 46 \& 47.

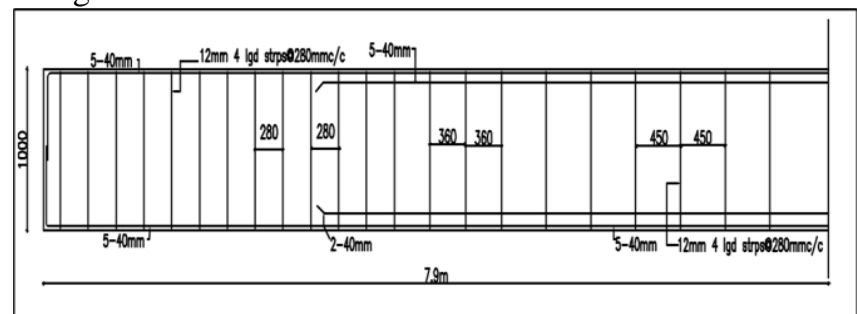

Fig. 46 Half L-section of Fulcrum Girder

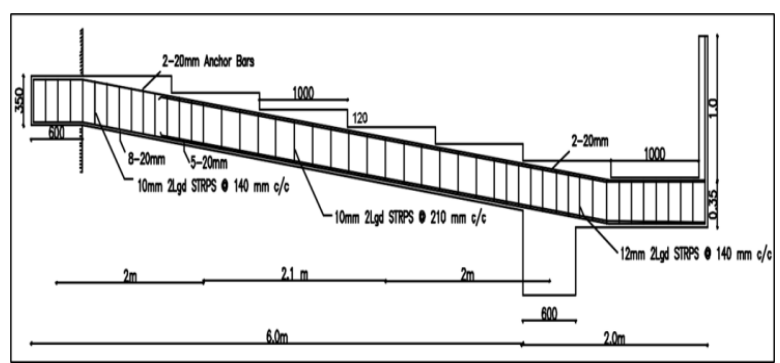

Fig. 47 L-section of Raker Beam

\section{Design of Base Plate}

The Bottom chord member of Truss is supported on RCC Column $1500 \mathrm{~mm}$ x $1500 \mathrm{~mm}$.

Axial force $(\mathrm{DL}+\mathrm{LL})=1670.233 \mathrm{kN}$

Uplift pressure due to wind load $=-158.813 \mathrm{kN}$

Bending Moment $=1455.969 \mathrm{kNm}$

Grade of concrete $(\mathrm{fck})=30 \mathrm{~N} / \mathrm{mm}^{2}$

Diameter of Bottom Chord $=350 \mathrm{~mm}$

Thickness of Bottom Chord $=8 \mathrm{~mm}$

Supported on RCC Column =

$1500 \mathrm{~mm} \times 1500 \mathrm{~mm}$

Class of Bolts for all connections $=8.8$

The Dimension of the Base plate provide is given in Fig. 48.

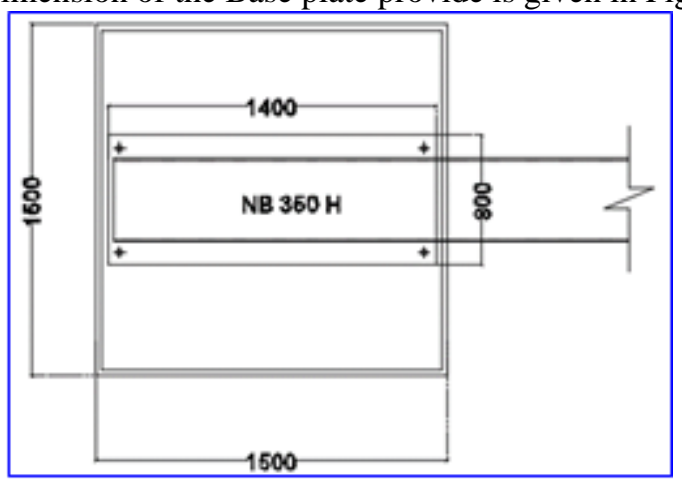

Fig 48 Plan of Base plate connection

The connection of the Base plate to RCC Column through Anchor Bolts is shown in Fig. 49 and the truss member connection to RCC Column is shown n Fig. 50.

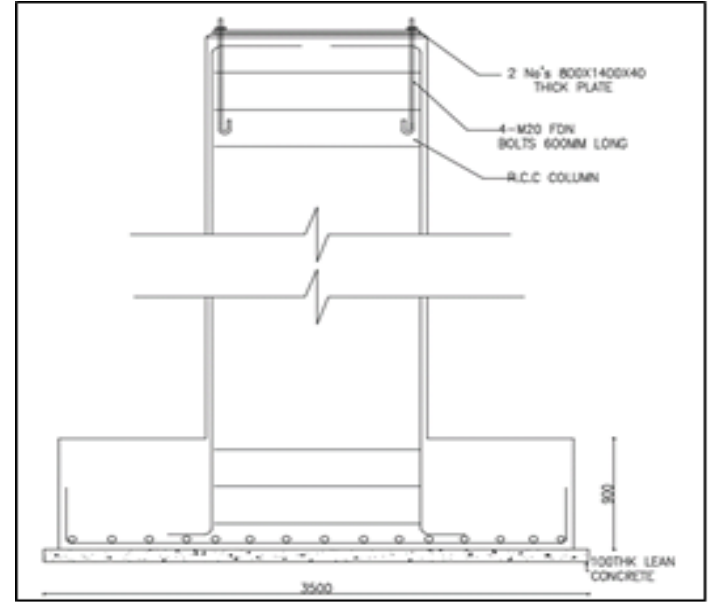

Fig 49 Anchor Bolts for Base plate connection

Published By:

Blue Eyes Intelligence Engineering and Sciences Publication (BEIESP)

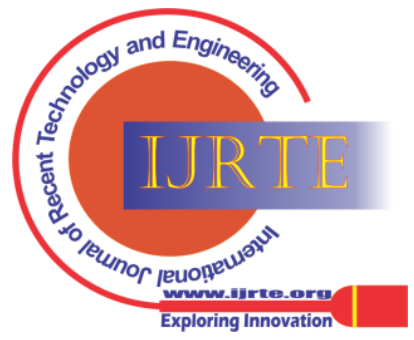




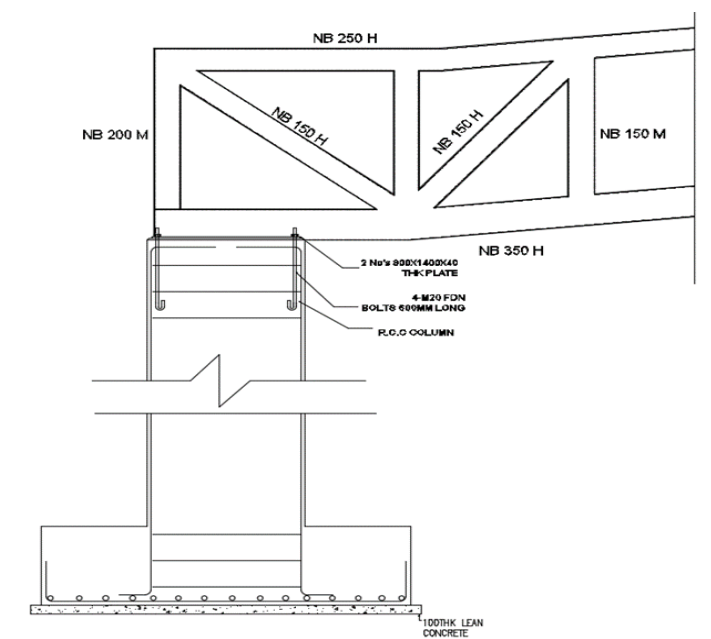

Fig 50 Truss member connection to RCC Column

\section{CONCLUSION}

Following Conclusions are drawn from the results of the Project work:

1. Introduction of Shell-like roof for Open Stadium which is used not only to protect the Game from Glare of Sunshine, Rain etc but also appears unique and attractive.

2.The Fundamental Time Period for Model-II i.e., Stadium with Shell roofing is found to be Increasing due to increase in height when compared to Model-I i.e, Stadium without Shell roofing,

3. From the results it is observed that the displacement due to Wind action in both $\mathrm{X}$ and $\mathrm{Z}$ direction reduces significantly by the introduction of Shell roof i.e., Model-II in comparison with Model-I (Stadium without Shell roof).

4. The Drift due to Wind action in both $\mathrm{X}$ and $\mathrm{Z}$ direction for Model-II reduces when compared to Model-I.

5. There is increase in Base Shear for Model-II when compared with Model-I due to introduction of Shell roof due to increase in Seismic weight of the structure.

6. The Story Drift due to Seismic action in both $\mathrm{X}$ and $\mathrm{Z}$ direction for Model-II reduces significantly when compared to Model-I.

7. Both RSA and THA techniques gave reduced Story displacement values for Model-II when compared to ModelI in contrast to ESA which gave reduced displacement values for Model-II in Z direction only.

\section{SCOPE FOR FURTHER STUDY}

1. Optimization studies on design and analysis of different type of steel truss stadium such as sub divided truss, Continuous truss and Arch truss can be carried out.

2. Combination of Steel truss Roof with Shell roof covering can be carried out for the stadiums such as Cricket Stadium, Rugby Stadium etc

\section{REFERENCES}

1. Gawande Mohini, Prof. D. G. Agrawal and Rajesh R. Joshi "Comparative Study on Analysis and Design of Roof Tubular Truss for Cricket Stadium", International Journal for Research in Applied Science \& Engineering Technology, Volume 8, Issue IV, Apr 2020 pp. 915-927

2. Thin Nwe Aye and Zaw Min Htun "Study on Analysis and Design of Football Stadium", International Journal of Scientific Engineering and Technology Research (IJSETR), Vol.03, Issue.12, June-2014, pp. 2621-2630
3. M. Rezai, A. Patterson and G. Hubick "Nonlinear Seismic Analysis and Retrofit of BC Place Stadium Using Rocking Foundation and Viscous Dampers", 2012 (10 pages)

4. 4. Nuno Martins, Elsa Caetano, Sandro Diord, Filipe Magalhaes and Alvaro Cunha "Dynamic monitoring of a stadium suspension roof Wind and temperature influence on modal parameters and structural response", Science Direct, Engineering Structures journal homepage: www.elsevier.com/locate/engstruct 59 (2014) pp 80-94

5. 5.. Yan Lin, Chang-lin Sun, Wei Jiang, Gang Du and Qing-wei Lin "The Design of Roof Structure for Bicycle Stadium in Jinan Olympic Sports Centre", Applied Mechanics and Materials Vols 94-96 (2011), pp 1105-1109

6. Dr Ola Adel Qasim “Analysis and Design of Steel Truss Stadium”, Research Gate 3237055202018 DOI:10.13140/RG.2.2.15447.98729 (58 pages)

7. Subramani.T, Sankar.P, Annadurai.K, Jothikannan.P and Raja.R "Planning, Analysing and Designing of Indoor Stadium Building by Using STAAD Pro", International Journal of Application or Innovation in Engineering \& Management (IJAIEM), Volume 8, Issue 3, March 2019 pp. 137-149

8. IS 456:2000 code of practice for "Plain and Reinforced Concrete 1893(Part 1): 2002 code of practice for "Criteria for Earthquake

9. Resistant Design of Structures"

10. N. C. Sinha and S. K. Roy "Fundamentals of Reinforced Concrete", $\mathrm{S}$

11. CHAND and Company (P) Limited-New Delhi

12. 11. S. K Duggal, "Limit State Design of Steel Structures", McGraw Hill

13. Education (India) Pvt Ltd, 2014

\section{AUTHORS PROFILE}

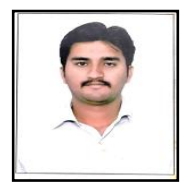

R Ashutosh V Kulkarni, M.Tech Scholar in Structura Engineering Department of Civil Engineering Poojya Doddappa Appa College of Engineering Kalaburagi 585102 Karnataka, India. Email: revoorashu8@gmail.com

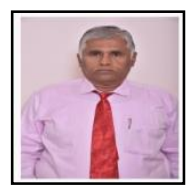

Dr Aravindkumar B Harwalkar, Associate Professo and Head, Department of Civil Engineering Poojya Doddappa Appa College of Engineering Kalaburagi $585102 \quad$ Karnataka, India. Email harwalkar_ab@yahoo.co.in
Published By:

Blue Eyes Intelligence Engineering and Sciences Publication (BEIESP)

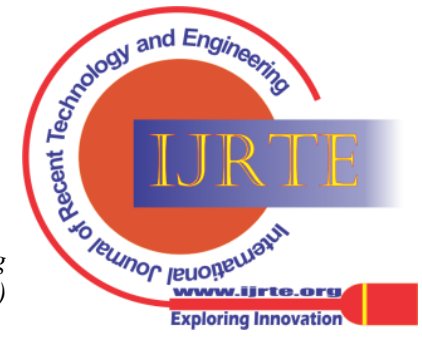

